\title{
Nimotuzumab combined with concurrent chemoradiotherapy benefits patients with advanced nasopharyngeal carcinoma
}

This article was published in the following Dove Press journal:

OncoTargets and Therapy

14 November 2017

Number of times this article has been viewed

\author{
Zhanzhan $\mathrm{Li}^{\prime}$ \\ Yanyan $\mathrm{Li}^{2}$ \\ Shipeng Yan $^{3}$ \\ Jun $\mathrm{Fu}^{\prime}$ \\ Qin Zhou' \\ Xinqiong Huang' \\ Liangfang Shen'
}

'Department of Oncology, Xiangya Hospital, Central South University, Changsha, China; ${ }^{2}$ Department of Nursing, Xiangya Hospital, Central South University, Changsha, China; ${ }^{3}$ Office of Tumor Prevention and Control, Hunan Provincial Tumor Hospital and the Affiliated Cancer Hospital of Xiangya School of Medicine, Central South University, Changsha, China
Correspondence: Liangfang Shen Department of Oncology, Xiangya Hospital, Central South University, 87 Xiangya Road, Kaifu District, Changsha 410008, Hunan Province, China $\mathrm{Tel} / \mathrm{fax}+8673189753332$

Email liangfangshen86@।26.com
Background: The potential benefits and possible risks associated with combined nimotuzumab and concurrent chemoradiotherapy in patients with advanced nasopharyngeal carcinoma (NPC) have yet to be determined.

Methods: The databases PubMed, Web of Science, China National Knowledge Infrastructure, and Wanfang were systematically searched through February 2017 for studies comparing combined nimotuzumab and chemoradiotherapy versus chemoradiotherapy alone in the treatment of NPC. Primary outcomes were complete and partial responses, and the secondary outcome was adverse reactions. The random-effect model was used to pool relative risks (RRs) and 95\% confidence intervals (CIs).

Results: Nine randomized control trials and six cohort studies were included in the final analysis ( $n=1,015$ patients). Compared with chemoradiotherapy alone, chemoradiotherapy combined with nimotuzumab was associated with an increased response rate $(\mathrm{RR}=1.11,95 \% \mathrm{CI}$ : 1.01-1.22). Combined treatment further reduced the occurrence rate of erythropenia $(\mathrm{RR}=0.11,95 \% \mathrm{CI}$ : $0.05-0.28)$ and neutropenia ( $R R=0.12,95 \% \mathrm{CI}: 0.05-0.27$ ). The differences in the rates of other complications were not significant.

Conclusion: Nimotuzumab combined with concurrent chemoradiotherapy is more effective in patients with advanced NPC than chemoradiotherapy alone. Patients receiving combination therapy did not have a higher rate of adverse reactions. Nimotuzumab can thus be recommended as an adjunct therapy in patients with advanced NPC.

Keywords: randomized controlled trial, cohort studies, nasopharyngeal carcinoma, relative risk, radiotherapy, chemoradiotherapy

\section{Introduction}

Nasopharyngeal carcinoma (NPC) is a common malignant tumor of the head and neck, especially in China. The World Health Organization estimates that $>80 \%$ of NPCs occur in China. ${ }^{1}$ In recent years, the use of intensity-modulated radiation therapy has increased the efficacy of treatment. The survival rate of patients with stage I or II NPC is $90 \%$, and the rates of recurrence and metastasis are $8.2 \%$ and $15.4 \%$, respectively. ${ }^{2,3}$ However, the primary lesion of NPC is often occult such that early detection, diagnosis, and treatment are challenging. Thus, at presentation, $>70 \%$ of NPC patients have stage III or IV disease. The most common form of treatment for these patients with advanced disease is radiotherapy, but its efficacy is poor and severe adverse reactions occur at high rates. ${ }^{4}$ Moreover, the rates of local recurrence and distant metastasis are as high as 50\%, and the 5-year survival rate for patients treated with radiotherapy alone is only $20 \%$. Indeed, the main reasons for treatment failure are recurrence and 
metastasis. Therefore, patients with advanced NPC are currently treated with concurrent chemotherapy or neoadjuvant therapy. ${ }^{5}$ Emerging randomized controlled trials (RCTs) recommend cisplatin, paclitaxel, or both for use in concurrent chemoradiotherapy. ${ }^{6,7}$ However, despite the considerable therapeutic benefits, concurrent chemoradiotherapy considerably increases the occurrence of severe toxicities, including nausea and vomiting, gastrointestinal reactions, and skin injury. ${ }^{8}$ Thus, there is an urgent need to identify more effective and tolerable agents for the treatment of advanced NPC.

Many types of cancers overexpress growth factors on the tumor cell surface. In the non-keratinizing form of NPC, $90 \%$ of the tumor cells are positive for epidermal growth factor receptor (EGFR). ${ }^{9}$ Altered EGFR signaling has been widely implicated in processes such as apoptosis, proliferation, metastasis, and invasion. ${ }^{10,11}$ Thus, targeted therapy against EGFR has been proposed as an adjunct to radiotherapy to improve the curability of NPC. Nimotuzumab is a humanized anti-EGFR mouse monoclonal antibody that reduces immunoreactivity and promotes radiosensitivity. In clinical trials, nimotuzumab combined with concurrent radiotherapy seemed to facilitate radiosensitivity and thus increase treatment efficacy while maintaining low toxicity. ${ }^{12,13}$ These findings indicate a synergistic effect of nimotuzumab combined with radiotherapy. The efficiency of this combined approach versus chemoradiotherapy alone has been examined in several RCTs and cohort studies, but no conclusions were reached regarding the potential benefits and possible risks in patients with advanced NPC. We therefore conducted a meta-analysis of the recent literature to assess the efficacy and safety of combined nimotuzumab with traditional concurrent chemoradiotherapy.

\section{Methods}

Ethical approval was not needed for the present study since it was a meta-analysis of previously published studies. The analysis was conducted in accordance with Preferred Reporting Items for Systematic Reviews and Meta-analysis Statement (PRISMA; Figure S1) guidelines and the Cochrane Handbook for Systematic Reviews of Interventions. Ethical approval was also not needed for this secondary study.

\section{Literature search}

We performed systematic electronic and manual searches of the relevant literature in PubMed, Web of Science, China National Knowledge Infrastructure, and Wanfang databases from their inception to February 28, 2017. The searches were conducted using the following medical subject headings and key words: "Nimotuzumab OR h-R3” AND "nasopharyngeal carcinoma OR NPC", "targeted therapy” AND "nasopharyngeal carcinoma OR NPC", "nasopharyngeal carcinoma OR NPC" AND "radiotherapy OR chemotherapy". Literature lists of reviews and relevant articles were also retrieved for potentially eligible studies. Only articles published in English and Chinese languages were included.

\section{Inclusion and exclusion criteria}

Two investigators independently performed the initial searches, excluding duplicates, and scanning the titles and abstracts of potentially eligible publications. The full text was then obtained for further screening. Any disagreement regarding the appropriateness of the study was solved by discussion and consensus. The criteria for study inclusion were as follows: (1) study design: RCT or cohort study; (2) population: patients with moderate or advanced NPC (stage $\geq$ III) as primarily confirmed by the pathological results (gold standard); (3) intervention: nimotuzumab combined with concurrent chemoradiotherapy in the experimental group and concurrent chemoradiotherapy alone in the control group; and (4) outcome: complete response (CR), partial response (PR), stable disease (SD), progressive disease (PD), or adverse reactions.

\section{Data extraction}

The collected data were entered into a standardized Excel sheet, extracted by ZZL, and checked by LFS. The following information was extracted: first author, year of publication, mean ages of the two study groups, numbers of male and female patients, sample size, clinical setting (inclusion criteria for the study population), clinical stage, therapeutic schedules of the trial and control groups, and outcomes. The primary outcomes were $\mathrm{CR}, \mathrm{PR}, \mathrm{SD}$, and $\mathrm{PD}$, and the secondary outcome was adverse reactions. Any discrepancies were resolved by consensus with the other investigators involved in this study.

\section{Assessment of quality}

Our study included RCTs and prospective cohort studies. The Newcastle-Ottawa Scale was used to assess the quality of non-randomized studies based on a "star system" ranking selection, comparability, and outcome. Selection included the exposed cohort, nonexposed cohort, and ascertainment of the exposure and outcome of interest. The outcomes included assessment, length of follow-up, and adequacy of follow-up. Studies with $\geq 7$ stars were considered to be of 
priority quality, those with $\geq 5$ stars of high quality, and those with $\leq 5$ stars of low quality. ${ }^{14}$

The Cochrane Collaboration's tool was used to assess the risk of bias in the RCTs. ${ }^{15}$ The risk was evaluated as high, low, or unclear according to the following items: random sequence generation, allocation concealment, blinding of participants and outcome assessment, incomplete outcome data, selective reporting, and other biases. Because blinding of the patients and clinicians in these trials was not possible, the studies were considered to have a high risk of bias when another risk item besides blinding was identified.

\section{Statistical analysis}

Relative risks (RRs) and 95\% confidence intervals (CIs) were used to calculate estimates of dichotomous outcomes. A value of 1 was considered to indicate beneficial effects for patients because the primary outcome was either CR or PR. The heterogeneity of the studies was assessed using the Cochran $Q$ and $I^{2}$ statistics. ${ }^{16}$ For the $I^{2}$ statistic, a value $>50 \%$ was considered to indicate a high level of heterogeneity.
The outcome data were pooled using the random-effect model for significant heterogeneity. The fixed-effect model was used for less significant heterogeneity. The risk of occurrence of 15 adverse reactions was also determined: nausea and vomiting, gastrointestinal reactions, skin injury, leucopenia, radiation dermatitis, mucosa reaction, declining hemoglobin, erythropenia, thrombocytopenia, liver injury, renal injury, neutropenia, myelosuppresion, hair loss, and fever. A sensitivity analysis was performed by sequentially excluding individual studies to assess the stability of the results. Publication bias was assessed by visually inspecting a funnel plot and using Egger's linear regression test. ${ }^{17-20}$ All statistical analyses were performed using Stata 14.0 (Stata Corp., College Station, TX, USA) and Review Manager 5.3 (Cochrane Center). $P$-value $<0.05$ was considered to indicate statistical significance.

\section{Results Study selection}

A flow chart of the study selection process is presented in Figure 1. Our initial search returned 386 results. No record

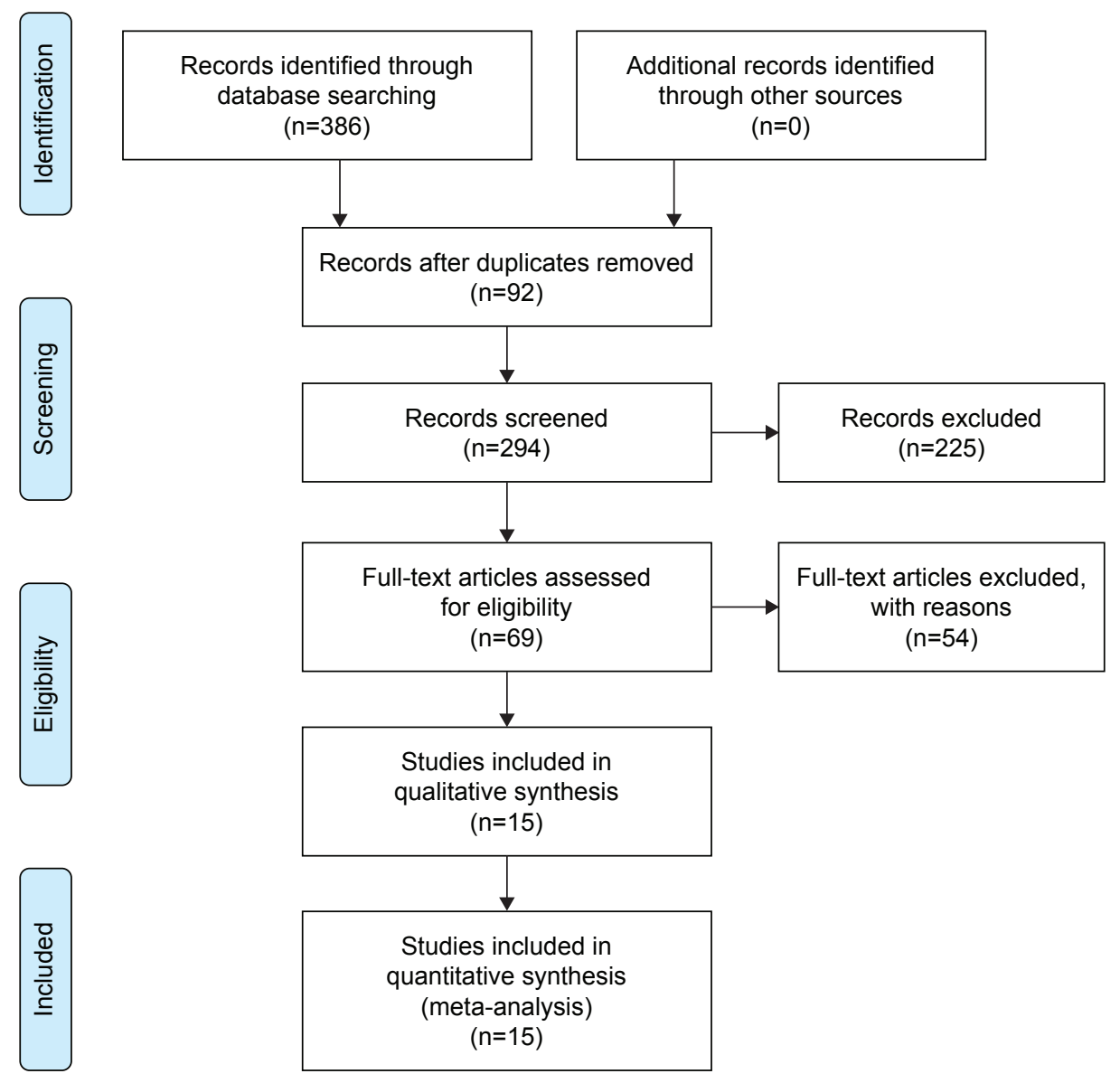

Figure I Flow diagram of studies selection process. 
was obtained from additional sources. After the removal of 92 duplicate records, 294 articles were screened for their titles and abstracts. After the full text of 69 articles eligible for inclusion was reviewed, nine RCTs and six cohort studies were finally included in the meta-analysis. ${ }^{4,21-34}$

\section{General characteristics of the included studies}

The general characteristics of the included studies are summarized in Table 1. The studies were published from 2012 to 2016, and the sample sizes ranged from 31 to 183 , with a total of 1,015 patients. In three of the 15 studies, nimotuzumab was combined with cisplatin and paclitaxel, in six studies with cisplatin and radiotherapy, in three studies with nedaplatin and radiotherapy, in two studies with paclitaxel and radiotherapy, and in one study with carboplatin and radiotherapy. All studies were conducted in adult patients. All outcomes were assessed within 1 year. Consistent with the finding of the World Health Organization that $80 \%$ of NPCs occur in China, all of the included studies were from this location. ${ }^{35}$

\section{Quality assessment}

Quality was assessed based on an assessment of the risk of bias (Figures S2 and S3). Among the nine RCTs, three were considered to have a low risk of bias, five an unclear risk, and one a high risk. The main sources of bias were related to allocation concealment, the blinding of participants and personnel, and outcome assessment. Each of the six cohort studies received $>5$ stars. The overall quality of the cohort studies was high (Table 2).

\section{Nimotuzumab and chemoradiotherapy versus chemoradiotherapy alone}

Fourteen studies with 877 NPC patients provided data on CRs and PRs. Compared with chemoradiotherapy alone, patients treated with nimotuzumab combined with chemoradiotherapy had a significantly improved response rate $(\mathrm{RR}=1.11,95 \% \mathrm{CI}: 1.01-1.22)$. The heterogeneity of the studies was $75 \%$ (Figure 2).

Figures 3-5 present the pooled results for adverse reactions. Compared with chemoradiotherapy alone, the combination of nimotuzumab and chemoradiotherapy did not lower the occurrence rate of nausea and vomiting ( $R R=0.74,95 \%$ CI: $0.39-1.42$ ), gastrointestinal reactions ( $R R=1.04,95 \%$ CI: $0.42-2.36$ ), skin injury ( $R R=0.82,95 \%$ CI: $0.39-1.70$ ),

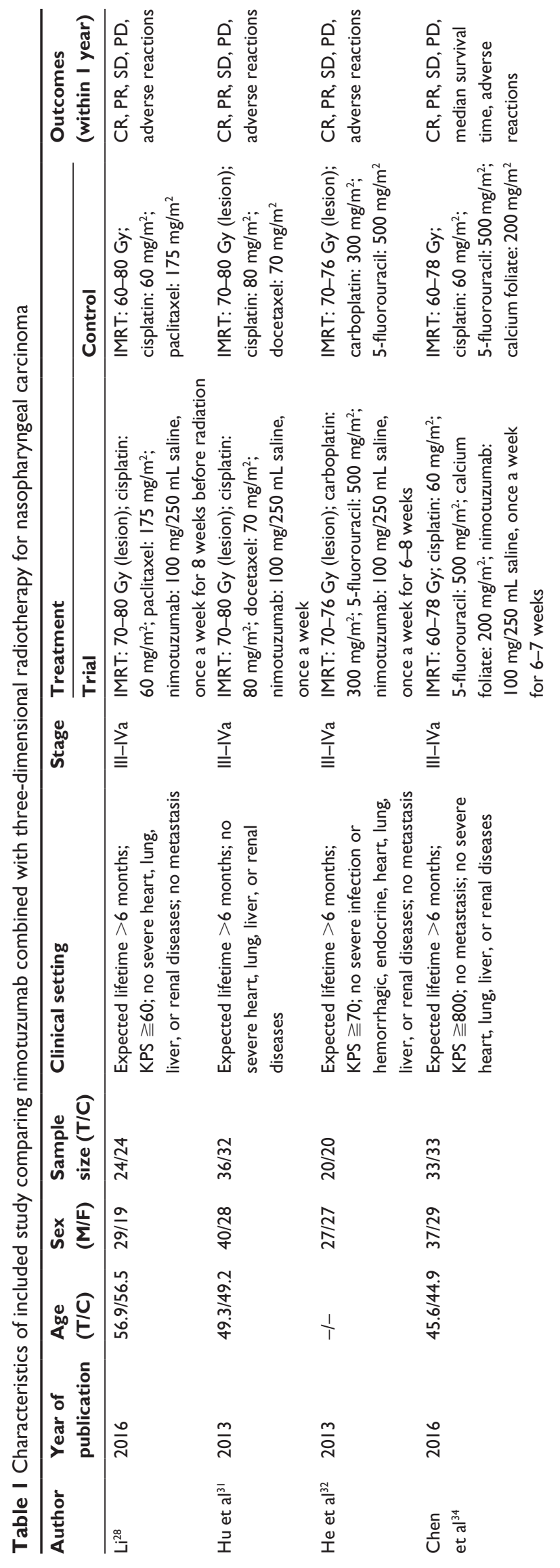




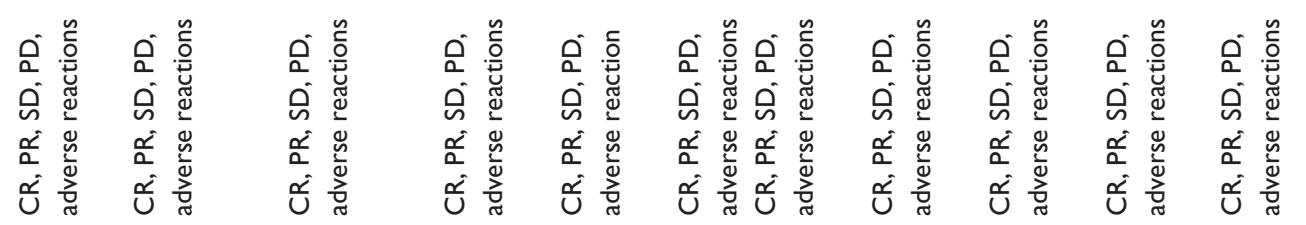

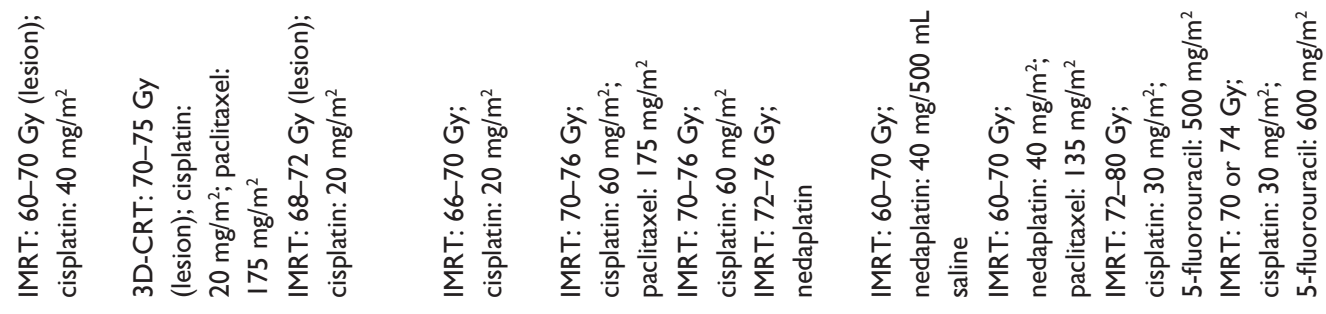

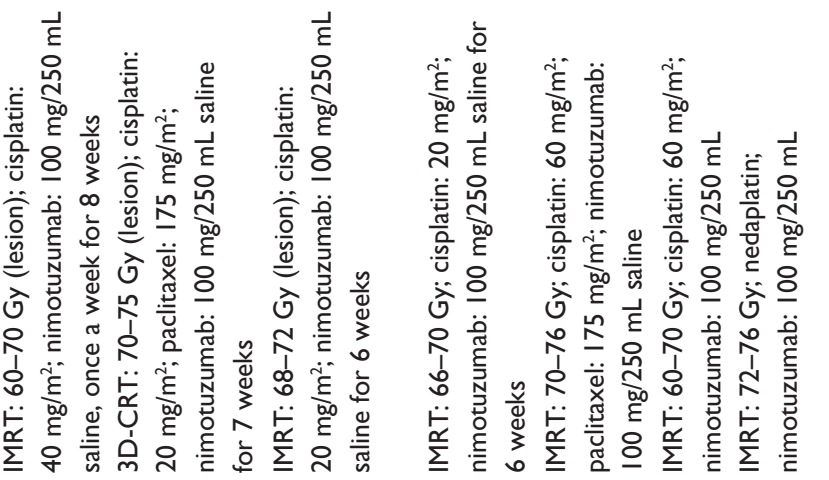

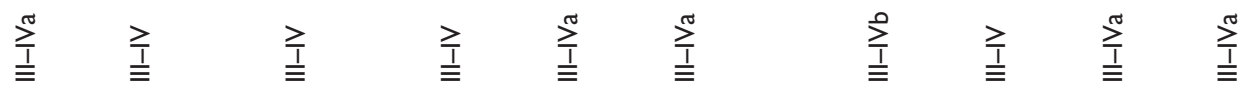

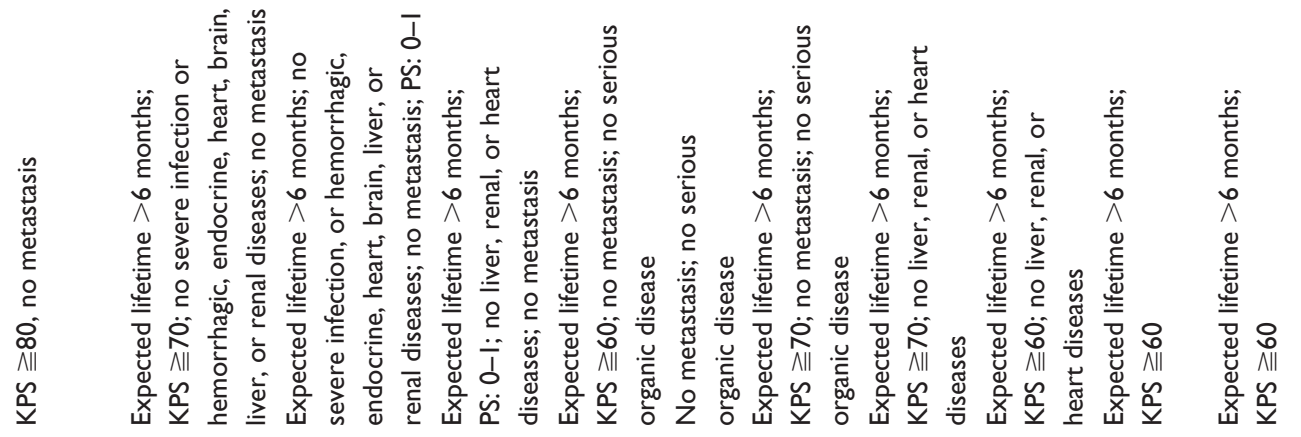

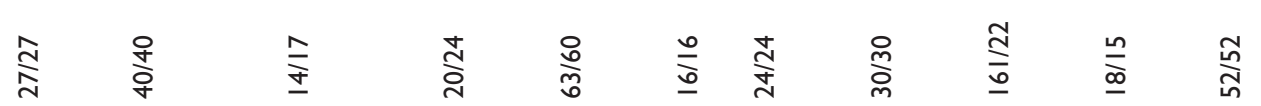
离

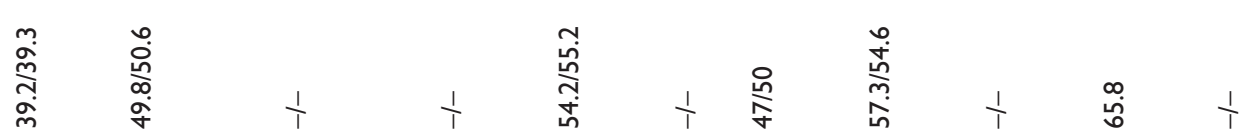

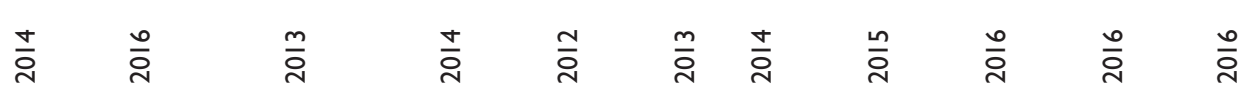

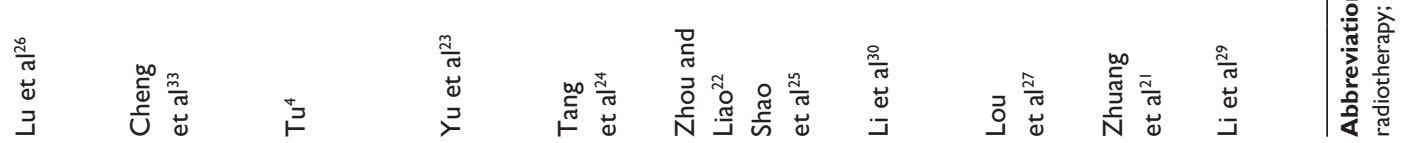


Table 2 Methodological quality assessment (risk of bias) of included studies by Newcastle-Ottawa Scale

\begin{tabular}{|c|c|c|c|c|c|c|c|c|c|}
\hline \multirow[t]{2}{*}{ Study } & \multicolumn{4}{|l|}{ Selection } & \multirow[t]{2}{*}{ Comparability } & \multicolumn{3}{|l|}{ Outcome } & \multirow{2}{*}{$\begin{array}{l}\text { Total } \\
\text { score }\end{array}$} \\
\hline & $\begin{array}{l}\text { Exposed } \\
\text { cohort }\end{array}$ & $\begin{array}{l}\text { Nonexposed } \\
\text { cohort }\end{array}$ & $\begin{array}{l}\text { Ascertainment } \\
\text { of exposure }\end{array}$ & $\begin{array}{l}\text { Outcome } \\
\text { of interest }\end{array}$ & & $\begin{array}{l}\text { Assessment } \\
\text { of outcome }\end{array}$ & $\begin{array}{l}\text { Length of } \\
\text { follow-up }\end{array}$ & $\begin{array}{l}\text { Adequacy } \\
\text { of follow-up }\end{array}$ & \\
\hline Li et $\mathrm{al}^{29}$ & $*$ & $*$ & $*$ & $*$ & $* *$ & $*$ & - & - & 7 \\
\hline Chen et $\mathrm{al}^{34}$ & $*$ & $*$ & $*$ & $*$ & $*$ & $*$ & - & - & 6 \\
\hline Lu et $\mathrm{al}^{26}$ & $*$ & $*$ & $*$ & $*$ & $* *$ & $*$ & - & - & 7 \\
\hline Li et $\mathrm{al}^{30}$ & $*$ & $*$ & $*$ & $*$ & $* *$ & $*$ & - & - & 7 \\
\hline Lou et $\mathrm{al}^{27}$ & $*$ & $*$ & $*$ & $*$ & $* *$ & $*$ & $*$ & - & 8 \\
\hline $\mathrm{Li}^{28}$ & $*$ & $*$ & $*$ & $*$ & $*$ & $*$ & - & - & 6 \\
\hline
\end{tabular}

Note: $* 1$ point; $* * 2$ points.

leucopenia $(\mathrm{RR}=1.43,95 \% \mathrm{CI}: 0.79-2.57)$, radiation dermatitis $(\mathrm{RR}=1.08,95 \% \mathrm{CI}: 0.15-7.74)$, mucosal reactions $(\mathrm{RR}=0.79,95 \% \mathrm{CI}: 0.31-2.02)$, declining hemoglobin $(\mathrm{RR}=0.99,95 \% \mathrm{CI}$ : 0.62-1.59), thrombocytopenia $(\mathrm{RR}=0.72,95 \% \mathrm{CI}: 0.36-1.45)$, liver injury $(\mathrm{RR}=1.12,95 \%$ CI: 0.54-2.30), renal injury $(\mathrm{RR}=0.97,95 \% \mathrm{CI}: 0.39-2.41)$, myelosuppression ( $\mathrm{RR}=1.14,95 \% \mathrm{CI}: 0.30-4.24)$, hair loss $(\mathrm{RR}=0.39,95 \% \mathrm{CI}: 0.02-9.73)$, or fever $(\mathrm{RR}=0.80,95 \%$ CI: 0.21-3.12). The results of the overall effect test were not significant $(P>0.05)$. However, the occurrence rates of erythropenia and neutropenia were significantly lower in the combined nimotuzumab group than in the chemoradiotherapy-alone group $(\mathrm{RR}=0.11,95 \% \mathrm{CI}: 0.05-0.28$; $\mathrm{RR}=0.12$, 95\% CI: 0.05-0.27).

Sensitivity analyses were conducted by sequentially excluding one study at a time. Figure 5 shows that the pooled estimation was not altered; therefore, the results were statistically robust.
Begg's and Egger's tests were used to test for publication bias. Begg's test did not detect publication bias $(Z=1.480$, $P=0.155)$, but Egger's test was based on an inspection of the funnel plot and formal statistical tests $(t=2.17$, $P=0.050)$. A trim-and-fill analysis showed that four studies were required to balance the asymmetry of the funnel plot (Figure 6).

\section{Discussion}

A comprehensive and systematic literature retrieval and meta-analysis of the eligible articles suggested that nimotuzumab combined with concurrent chemoradiotherapy benefits patients with advanced NPC and is better than chemoradiotherapy alone. The two treatment methods did not differ significantly in the occurrence rates of most of the adverse reactions. However, combined therapy lowered the occurrence rates of erythropenia and neutropenia compared with chemoradiotherapy alone.

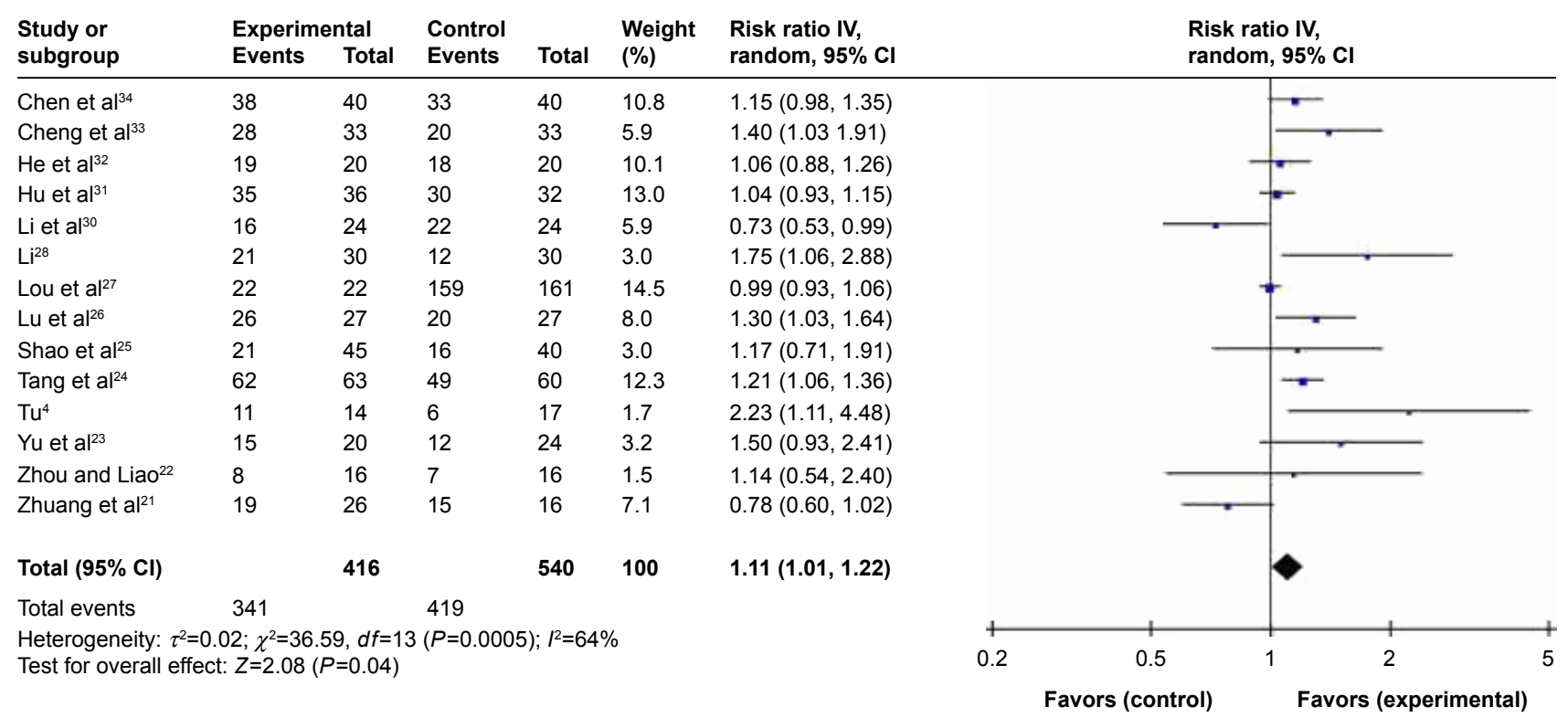

Figure 2 Forest plot of nimotuzumab combined with concurrent chemoradiotherapy versus chemoradiotherapy alone in advanced NPC. Abbreviations: NPC, nasopharyngeal carcinoma; IV, inverse variance; $\mathrm{Cl}$, confidence interval. 


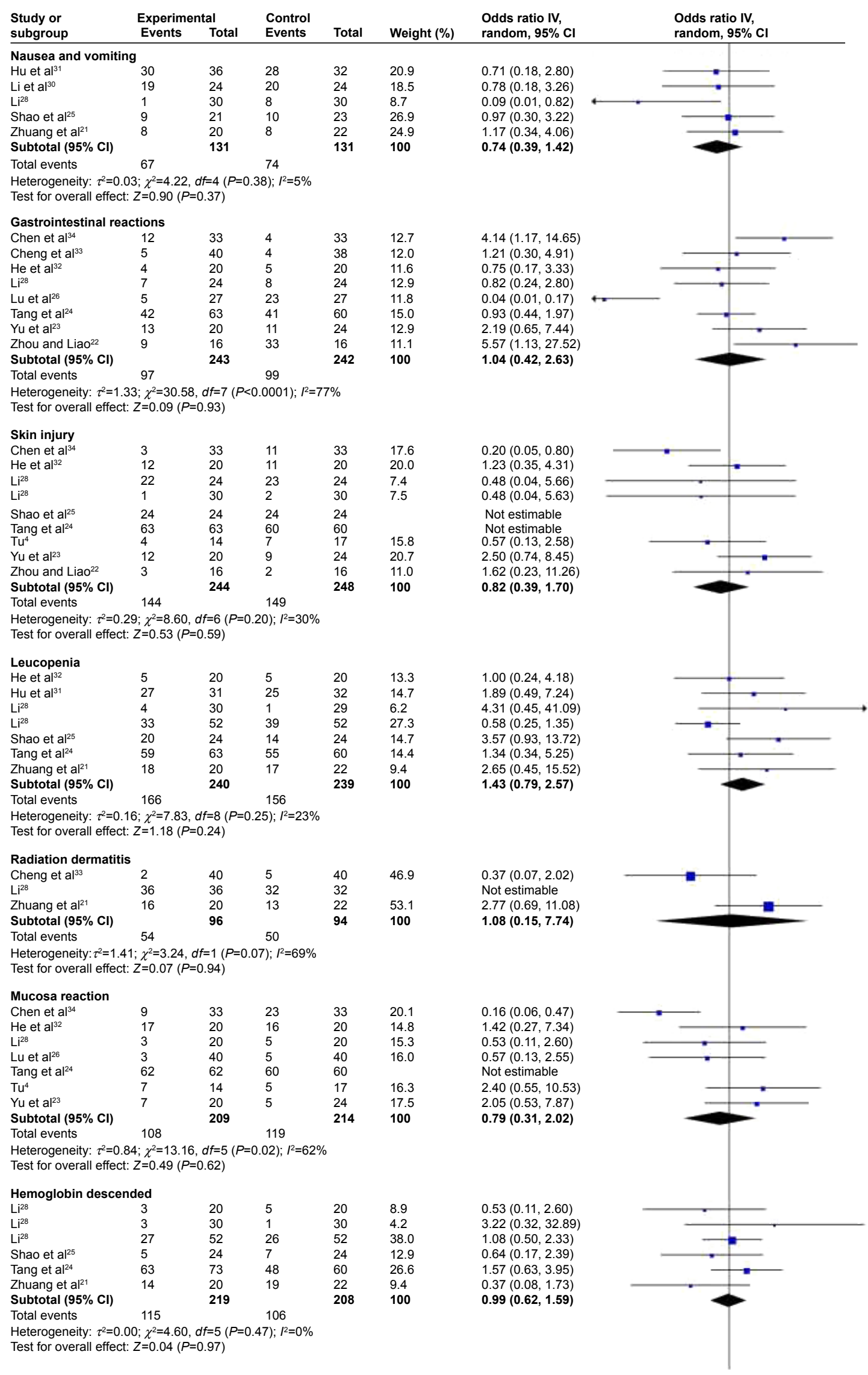

Figure 3 Forest plot of adverse reactions between nimotuzumab group and chemoradiotherapy alone.

Abbreviations: IV, inverse variance; $\mathrm{Cl}$, confidence interval. 


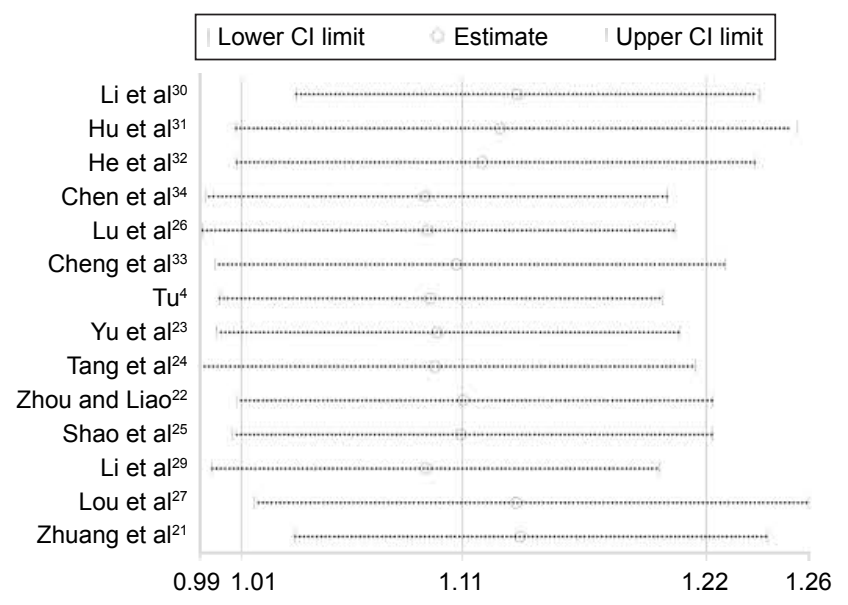

Figure 4 Forest plot of adverse reactions between nimotuzumab group and chemoradiotherapy alone.

Several studies have examined the efficacy of combined nimotuzumab therapy, but ours is the first to comprehensively evaluate the efficacy of nimotuzumab combined with chemoradiotherapy. In previous studies of head and neck carcinomas and NPC, concurrent chemoradiotherapy was shown to be more effective than radiotherapy or chemotherapy alone. However, these cases are rare, as most patients with these cancers do not need concurrent chemoradiotherapy. The 5-year overall survival rate of patients with stage II NPC treated with concurrent chemoradiotherapy is $94.5 \%$, and the treatment plan is effective and feasible. The addition of nimotuzumab to the standard treatment protocol increases the $\mathrm{CR}$ rate without increasing the occurrence of adverse reactions. Our results support these findings.

Platinum has always been the main chemotherapeutic agent used to treat NPC, serving as a sensitizer during chemotherapy, radiotherapy, or both. Although patients with NPC greatly benefit from concurrent chemoradiotherapy, relapses and metastases are frequent, especially for patients with advanced NPC. ${ }^{6}$ Thus, there is an urgent need for adjunct therapies for advanced disease. Nimotuzumab is a human monoclonal antibody that specifically recognizes EGFR-binding sites and blocks other factors from binding to them. The Chinese government approved clinical trials of nimotuzumab in 2002. By binding to extracellular segments of EGFR, nimotuzumab blocks its activation pathways, including those linked to tumor angiogenesis factors, and potently inhibits tumor proliferation and metastasis. ${ }^{36,37}$ Our results suggest that nimotuzumab synergizes with chemoradiotherapy, as reported in clinical populations. In the study of Nabid et al, the CR of patients treated with nimotuzumab for locally advanced squamous cell cancer of the head and neck after radiotherapy was $70 \%{ }^{38}$ Crombet et al reported a 3-year survival rate for nimotuzumab combined with radiotherapy of $66.7 \%$, which is significantly higher than that for radiotherapy alone, and fewer adverse reactions. ${ }^{39}$ The Chinese Academy of Medical Sciences conducted a multicenter Phase II RCT to assess the efficacy and adverse reactions of nimotuzumab combined with radiotherapy in patients with advanced NPC. In that study, the 3-year survival rate was significantly higher in the treated than in the control group ( $84.3 \%$ versus $77.6 \%$ ), a result attributed to the binding ability of nimotuzumab. ${ }^{40}$ The affinity of nimotuzumab for EGFR is several times higher than that for the endogenous ligand. Moreover, the occurrence of erythropenia and neutropenia was lower. ${ }^{31}$ However, these results were specifically reported in only two studies and remain to be confirmed.

A major strength of our meta-analysis is that it was conducted in accordance with PRISMA guidelines and the recommendations outlined in the Cochrane Center handbook. Another strength is the study population, which consisted of first-visit patients with advanced NPC. Our sensitivity analyses confirmed the findings of the included studies. However, there are several limitations that still need to be addressed. First, the studies included in our meta-analysis were performed in different clinical settings, and the standard treatment plans were different (nimotuzumab was combined with cisplatin, paclitaxel, or nedaplatin). This potential heterogeneity must be taken into account in interpreting the results of our analysis. Second, most of the included RCTs were not blinded, which may have caused performance and detection biases. Third, some adverse reactions were examined in only two or three studies; thus, the results may be unstable. Finally, the included studies used experimental arms, including cisplatin and paclitaxel, as the control arms. While their findings address these patients, for others the results remain to be determined.

In conclusion, the use of nimotuzumab combined with concurrent chemoradiotherapy was shown to benefit patients with advanced NPC and was better than chemoradiotherapy alone. Moreover, combined therapy did not increase the rates of adverse reactions. Nimotuzumab can therefore be recommended as adjunct therapy in patients with advanced NPC. 


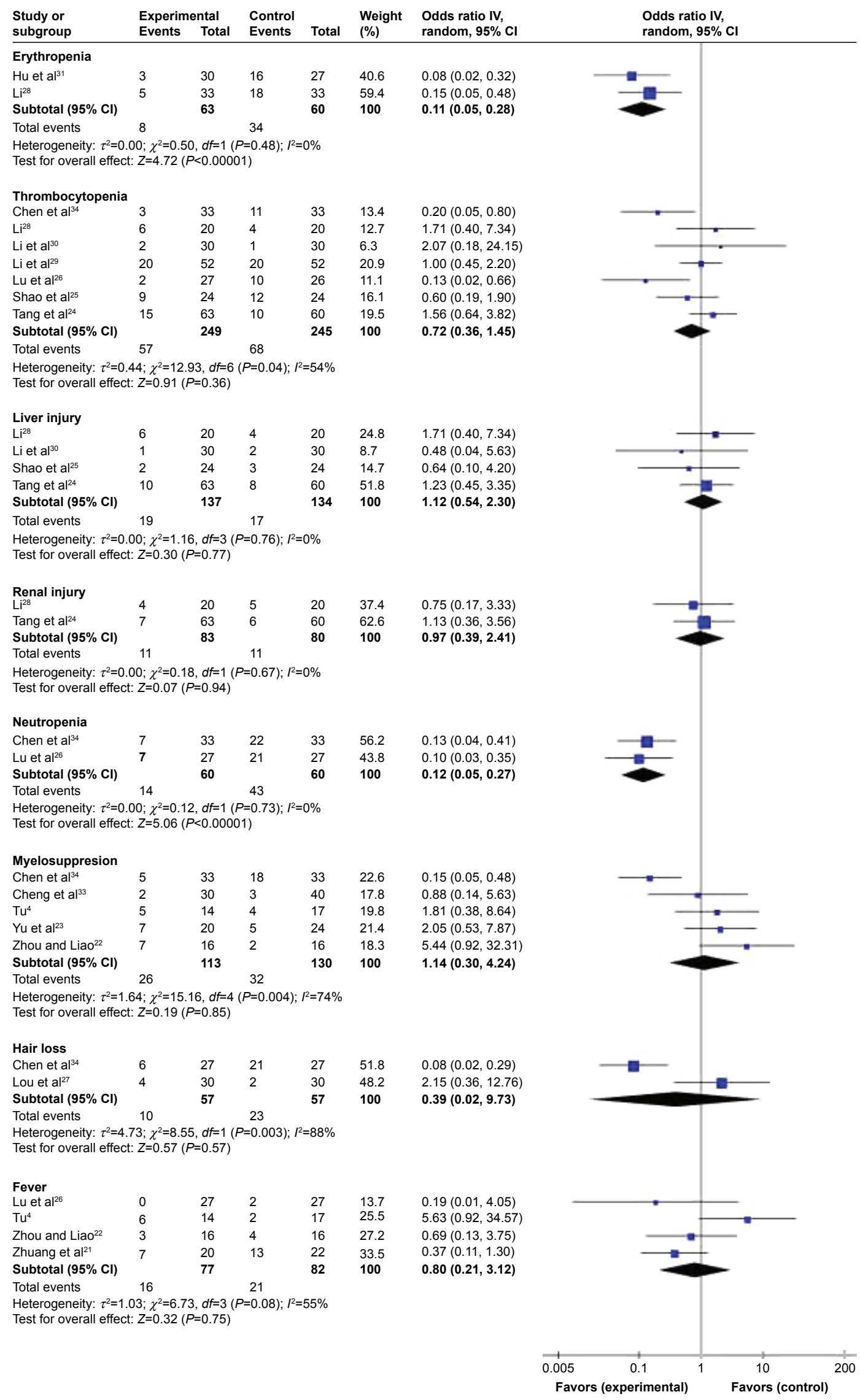

Figure 5 Sensitivity analysis of the pooled estimation.

Abbreviations: IV, inverse variance; $\mathrm{Cl}$, confidence interval. 


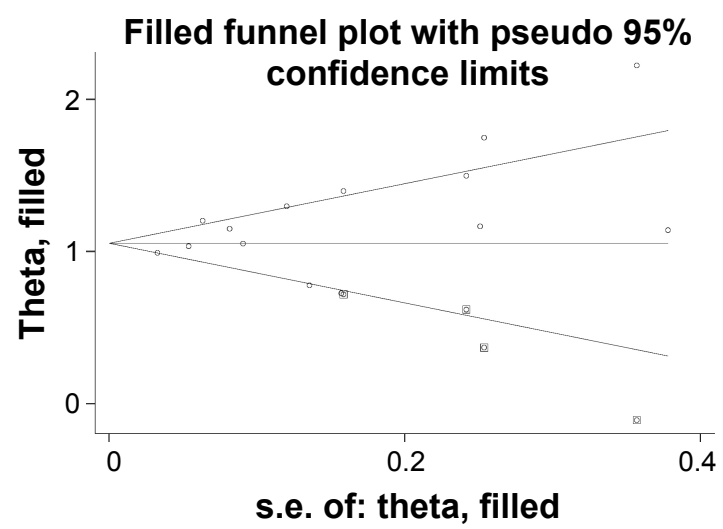

Figure 6 Deek's funnel plot to evaluate the publication bias. Abbreviation: s.e., standard error.

\section{Acknowledgments}

The authors thank all their colleagues working in the Department of Oncology, Xiangya Hospital, Central South University. This research was funded by National Natural Science Foundation (81602683) and Hunan Provincial Natural Science Foundation (2015JJ4055).

\section{Disclosure}

The authors report no conflicts of interest in this work.

\section{References}

1. Chen W, Zheng R, Baade PD, et al. Cancer statistics in China, 2015. CA Cancer J Clin. 2016;66(2):115-132.

2. Huang TL, Chien CY, Tsai WL, et al. Long-term late toxicities and quality of life for survivors of nasopharyngeal carcinoma treated with intensity-modulated radiotherapy versus non-intensity-modulated radiotherapy. Head Neck. 2016;38 Suppl 1:E1026-E1032.

3. Su SF, Han F, Zhao C, et al. Long-term outcome of nasopharyngeal carcinoma patients treated with intensity-modulated radiotherapy. Chin J Cancer Prev Treat. 2013;20(11):853-858.

4. Tu BJ. Clinical studies of Montezuma combined with cisplatin and three-dimensional conformal radiotherapy chemotherapy in the treatment of nasopharyngeal carcinoma. Guangzhou University; 2013. Available from: http://d.g.wanfangdata.com.cn/Thesis_D375768.aspx. Accessed November 1, 2017.

5. Ou Yang PY, Xie C, Mao YP, et al. Significant efficacies of neoadjuvant and adjuvant chemotherapy for nasopharyngeal carcinoma by metaanalysis of published literature-based randomized, controlled trials. Ann Oncol. 2013;24(8):2136-2146.

6. Lee AW, Tung SY, Chua DT, et al. Randomized trial of radiotherapy plus concurrent-adjuvant chemotherapy vs radiotherapy alone for regionally advanced nasopharyngeal carcinoma. J Natl Cancer Inst. 2010; 102(15):1188-1198.

7. Chan AT, Leung SF, Ngan RK, et al. Overall survival after concurrent cisplatin-radiotherapy compared with radiotherapy alone in locoregionally advanced nasopharyngeal carcinoma. J Natl Cancer Inst. 2005;97(7): 536-539.

8. Browman GP, Hodson DI, Mackenzie RJ, Bestic N, Zuraw L; Cancer Care Ontario Practice Guideline Initiative Head and Neck Cancer Disease Site Group. Choosing a concomitant chemotherapy and radiotherapy regimen for squamous cell head and neck cancer: a systematic review of the published literature with subgroup analysis. Head Neck. 2001;23(7):579-589.

9. Zhang ZC, Fu S, Wang F, Wang HY, Zeng YX, Shao JY. Oncogene mutational profile in nasopharyngeal carcinoma. Onco Targets Ther. 2014;7:457-467.
10. Ma BB, Poon TC, To KF, et al. Prognostic significance of tumor angiogenesis, Ki 67, p53 oncoprotein, epidermal growth factor receptor and HER2 receptor protein expression in undifferentiated nasopharyngeal carcinoma - a prospective study. Head Neck. 2003;25(10):864-872.

11. Chua DT, Nicholls JM, Sham JS, Au GK. Prognostic value of epidermal growth factor receptor expression in patients with advanced stage nasopharyngeal carcinoma treated with induction chemotherapy and radiotherapy. Int J Radiat Oncol Biol Phys. 2004;59(1):11-20.

12. Vallath S, Hynds RE, Succony L, Janes SM, Giangreco A. Targeting EGFR signalling in chronic lung disease: therapeutic challenges and opportunities. Eur Respir J. 2014;44(2):513-522.

13. Nicholas MK, Lukas RV, Chmura S, Yamini B, Lesniak M, Pytel P. Molecular heterogeneity in glioblastoma: therapeutic opportunities and challenges. Semin Oncol. 2011;38(2):243-253.

14. Wells GA, Shea B, O'Connell D, et al. The Newcastle-Ottawa Scale (NOS) for assessing the quality of non-randomized studies in metaanalysis. Available from: http://www.ohri.ca/programs/clinical_ epidemiology/oxford.asp. Accessed December 10, 2015.

15. Higgins JP, Altman DG, Gøtzsche PC, et al; Cochrane Bias Methods Group; Cochrane Statistical Methods Group. The Cochrane Collaboration's tool for assessing risk of bias in randomized trials. BMJ. 2011; 343:d5928.

16. Higgins JP, Thompson SG, Deeks JJ, Altman DG. Measuring inconsistency in meta-analyses. BMJ. 2003;327(7414):557-560.

17. Song F, Gilbody S. Bias in meta-analysis detected by a simple, graphical test. Increase in studies of publication bias coincided with increasing use of meta-analysis. BMJ. 1998;316(7129):471.

18. Begg CB, Mazumdar M. Operating characteristics of a rank correlation test for publication bias. Biometrics. 1994;50(4):1088-1101.

19. Li Z, Zhou Q, Li Y, Fu J, Huang X, Shen L. Growth hormone replacement therapy reduces risk of cancer in adult with growth hormone deficiency: a meta-analysis. Oncotarget. 2016;7(49):81862-81869.

20. Li Z, Zhou Q, Li Y, et al. Mean cerebral blood volume is an effective diagnostic index of recurrent and radiation injury in glioma patients: a meta-analysis of diagnostic test. Oncotarget. 2017;8(9):15642-15650.

21. Zhuang WJ, Liu CH, Situ HR, et al. Clinical observation and evaluation of the combination of nimotuzumab with radiotherapy and cisplatin + $5 \mathrm{FU}$ in the treatment of elderly patients with nasopharyngeal carcinoma. Elderly Med Health Care. 2016;22(5):309-312.

22. Zhou TZ, Liao ZW. Clinical study of nimotuzumab and three dimensional conformal radiotherapy in the treatment of recurrent nasopharyngeal carcinoma. Inter Med Health Guidance News. 2013;19(21): 3257-3260.

23. Yu HW, Zhuag YJ, Yu F, Liao ZW, Zhou TC. Clinical study of nimotuzumab combined with cisplatin and three-dimensional conformal radiotherapy in treatment of nasopharyngeal carcinoma. Guangxi Med J. 2014;36(7):882-884.

24. Tang WB, Yang W, Cao Y, et al. Effect of nimotuzumab combined with radiotherapy and chemotherapy for locally advanced nasopharyngeal carcinoma. Guangdong Med. 2012;33(11):1658-1662.

25. Shao JF, Li SP, Lian YN, Mao JX, Mo YM. Clinical study of nimotuzumab plus nadaplatin combined with concurrent chemoradiotherapy for locally advanced nasopharyngeal carcinoma. Modern Med J Chin. 2014;4(1):23-26.

26. Lu H, Ni FC, Liu LY, Wang Q, Si XY. Nimotuzumab concurrent radiotherapy and cisplatin chemotherapy in advanced nasopharyngeal carcinoma. Antitumor Pharmacy. 2014;1:50-53.

27. Lou F, Yang P, Zhang R, et al. Comparative study of nimotuzumab with radio-chemotherapy and radio-chemotherapy alone in the treatment of locally advanced nasopharyngeal carcinoma. J Clin Res. 2016;33(5): 933-935.

28. Li YL. Effects of nimotuzumab with cisplatin and chemoradiotherapy for advanced nasopharyngeal carcinoma. J Med Forum. 2016; 36(4):155-156.

29. Li HM, Li P, Qian YJ, et al. A retrospective paired study: efficacy and toxicity of nimotuzumab versus cisplatin concurrent with radiotherapy in nasopharyngeal carcinoma. BMC Cancer. 2016;16(1):946. 
30. Li D, Bai Y, Xie K, Ao R. Efficacy and safety of nimotuzumab combined with nedaplatin and three-dimensional conformal concurrent radiotherapy for nasopharyngeal cancer chemotherapy and the impact of TGF- $\beta 1$, S100A8 and S100A9. J Med Res. 2015;44(11):136-139.

31. Hu JX, Gu WG, He ZR, Luo HT, Xu M. Short-term effect of nimotuzumab combined with chemoradiotherapy for advanced nasopharyngeal carcinoma. Guangdong Med J. 2013;34(13):2094-2096.

32. He N, Si YF, Sun YJ, et al. Effect of nimotuzumab combined with concurrent chemoradiotherapy for locally advanced nasopharyngeal carcinoma. Guangxi Med J. 2013;35(7):834-837.

33. Cheng J, Xun X, Li GH. Clinical utility of nimotuzumab with cisplatin and chemoradiotherapy in advanced nasopharyngeal carcinoma. Hebei Med J. 2016;22(2):213-215.

34. Chen YJ, Quan F, Wang LJ, Li HH. Clinical effect of nimotuzumab combined with cisplatin concurrent chemoradiotherapy in the treatment of advanced nasopharyngeal carcinoma. China Med Herald. 2016; 13(3):118-121.

35. WHO. Cancer country profiles 2014. Available from: http://who.int/ cancer/country-profiles/en/. Accessed March 7, 2017.

36. Gondhowiardjo S, Muthalib A, Khotimah S, Rachman A. Nimotuzumab combined with radiotherapy reduces primary tumor and nodal volume in advanced undifferentiated nasopharyngeal carcinoma. Asia Pac J Clin Oncol. 2009;5(3):175-180.
37. Kameswaran M, Samuel G, Dev Sarma H, Shinde SN, Dash A, Venkatesh M. (131)I-Nimotuzumab - a potential radioimmunotherapeutic agent in treatment of tumors expressing EGFR. Appl Radiat Isot. 2015;102:98-102.

38. Nabid A, Ganguly P, Venkatesan V, et al. A phase I dose escalation study of a humanized monoclonal antibody to EGFR (hR3) in patients with locally advanced squamous cell cancer of the head and neck (SCCHN) treated with radiotherapy. Int J Radiat Oncol Biol Phys. 2002; 54(2 Suppl):288.

39. Crombet T, Neninger E, Catala M, et al. Epidermal growth factor based cancer vaccine for non-small cell lung cancer therapy: report from a phase I scale up trial. Eur J Cancer. 2002;38 Suppl 7:S137.

40. Huang XD, Yi JL, Gao L, et al. [Multi-center phase II clinical trial of humanized anti-epidermal factor receptor monoclonal antibody h-R3 combined with radiotherapy for locoregionally advanced nasopharyngeal carcinoma]. Zhonghua Zhong Liu Za Zhi. 2007;29(3):197-201. Chinese. 


\section{Supplementary materials}

\section{PRISMA 2009 checklist}

\begin{tabular}{|c|c|c|c|}
\hline Section/topic & \# & Checklist item & Reported on page \# \\
\hline \multicolumn{4}{|l|}{ Title } \\
\hline Title & 1 & Identify the report as a systematic review, meta-analysis, or both. & 1 \\
\hline \multicolumn{4}{|l|}{ Abstract } \\
\hline $\begin{array}{l}\text { Structured } \\
\text { summary }\end{array}$ & 2 & $\begin{array}{l}\text { Provide a structured summary including, as applicable: background; objectives; data } \\
\text { sources; study eligibility criteria, participants, and interventions; study appraisal and } \\
\text { synthesis methods; results; limitations; conclusions and implications of key findings; } \\
\text { systematic review registration number. }\end{array}$ & $2-3$ \\
\hline \multicolumn{4}{|l|}{ Introduction } \\
\hline Rationale & 3 & Describe the rationale for the review in the context of what is already known. & 4 \\
\hline Objectives & 4 & $\begin{array}{l}\text { Provide an explicit statement of questions being addressed with reference to } \\
\text { participants, interventions, comparisons, outcomes, and study design (PICOS). }\end{array}$ & 5 \\
\hline \multicolumn{4}{|l|}{ Methods } \\
\hline $\begin{array}{l}\text { Protocol and } \\
\text { registration }\end{array}$ & 5 & $\begin{array}{l}\text { Indicate if a review protocol exists, if and where it can be accessed (eg, Web address), } \\
\text { and, if available, provide registration information including registration number. }\end{array}$ & $5-6$ \\
\hline Eligibility criteria & 6 & $\begin{array}{l}\text { Specify study characteristics (eg, PICOS, length of follow-up) and report } \\
\text { characteristics (eg, years considered, language, publication status) used as criteria for } \\
\text { eligibility, giving rationale. }\end{array}$ & $6-7$ \\
\hline $\begin{array}{l}\text { Information } \\
\text { sources }\end{array}$ & 7 & $\begin{array}{l}\text { Describe all information sources (eg, databases with dates of coverage, contact with } \\
\text { study authors to identify additional studies) in the search and date last searched. }\end{array}$ & $6-7$ \\
\hline Search & 8 & $\begin{array}{l}\text { Present full electronic search strategy for at least one database, including any limits } \\
\text { used, such that it could be repeated. }\end{array}$ & 6 \\
\hline Study selection & 9 & $\begin{array}{l}\text { State the process for selecting studies (ie, screening, eligibility, included in systematic } \\
\text { review, and, if applicable, included in the meta-analysis). }\end{array}$ & 6 \\
\hline $\begin{array}{l}\text { Data collection } \\
\text { process }\end{array}$ & 10 & $\begin{array}{l}\text { Describe method of data extraction from reports (eg, piloted forms, independently, } \\
\text { in duplicate) and any processes for obtaining and confirming data from investigators. }\end{array}$ & 7 \\
\hline Data items & 11 & $\begin{array}{l}\text { List and define all variables for which data were sought (eg, PICOS, funding sources) } \\
\text { and any assumptions and simplifications made. }\end{array}$ & 7 \\
\hline $\begin{array}{l}\text { Risk of bias in } \\
\text { individual studies }\end{array}$ & 12 & $\begin{array}{l}\text { Describe methods used for assessing risk of bias of individual studies (including } \\
\text { specification of whether this was done at the study or outcome level), and how this } \\
\text { information is to be used in any data synthesis. }\end{array}$ & $6-7$ \\
\hline $\begin{array}{l}\text { Summary } \\
\text { measures }\end{array}$ & 13 & State the principal summary measures (eg, risk ratio, difference in means). & $7-8$ \\
\hline $\begin{array}{l}\text { Synthesis of } \\
\text { results }\end{array}$ & 14 & $\begin{array}{l}\text { Describe the methods of handling data and combining results of studies, if done, } \\
\text { including measures of consistency }\left(\mathrm{eg}, \mathrm{I}^{2}\right) \text { for each meta-analysis. }\end{array}$ & $7-8$ \\
\hline $\begin{array}{l}\text { Risk of bias } \\
\text { across studies }\end{array}$ & 15 & $\begin{array}{l}\text { Specify any assessment of risk of bias that may affect the cumulative evidence } \\
\text { (eg, publication bias, selective reporting within studies). }\end{array}$ & 8 \\
\hline $\begin{array}{l}\text { Additional } \\
\text { analyses }\end{array}$ & 16 & $\begin{array}{l}\text { Describe methods of additional analyses (eg, sensitivity or subgroup analyses, } \\
\text { meta-regression), if done, indicating which were pre-specified. }\end{array}$ & 8 \\
\hline \multicolumn{4}{|l|}{ Results } \\
\hline Study selection & 17 & $\begin{array}{l}\text { Give numbers of studies screened, assessed for eligibility, and included in the review, } \\
\text { with reasons for exclusions at each stage, ideally with a flow diagram. }\end{array}$ & 9 \\
\hline $\begin{array}{l}\text { Study } \\
\text { characteristics }\end{array}$ & 18 & $\begin{array}{l}\text { For each study, present characteristics for which data were extracted (eg, study size, } \\
\text { PICOS, follow-up period) and provide the citations. }\end{array}$ & $9-14$ \\
\hline $\begin{array}{l}\text { Risk of bias } \\
\text { within studies }\end{array}$ & 19 & $\begin{array}{l}\text { Present data on risk of bias of each study and, if available, any outcome level } \\
\text { assessment (see item 12). }\end{array}$ & 15 \\
\hline
\end{tabular}

Figure SI (Continued) 
PRISMA 2009 checklist

\begin{tabular}{|c|c|c|c|}
\hline Section/topic & \# & Checklist item & Reported on page \# \\
\hline $\begin{array}{l}\text { Results of } \\
\text { individual studies }\end{array}$ & 20 & $\begin{array}{l}\text { For all outcomes considered (benefits or harms), present, for each study: (a) simple } \\
\text { summary data for each intervention group (b) effect estimates and confidence } \\
\text { intervals, ideally with a forest plot. }\end{array}$ & 15 \\
\hline $\begin{array}{l}\text { Synthesis of } \\
\text { results }\end{array}$ & 21 & $\begin{array}{l}\text { Present results of each meta-analysis done, including confidence intervals and } \\
\text { measures of consistency. }\end{array}$ & 16 \\
\hline $\begin{array}{l}\text { Risk of bias } \\
\text { across studies }\end{array}$ & 22 & Present results of any assessment of risk of bias across studies (see item 15). & $16-17$ \\
\hline $\begin{array}{l}\text { Additional } \\
\text { analysis }\end{array}$ & 23 & $\begin{array}{l}\text { Give results of additional analyses, if done (eg, sensitivity or subgroup analyses, } \\
\text { meta-regression [see item 16]). }\end{array}$ & 17 \\
\hline \multicolumn{4}{|l|}{ Discussion } \\
\hline $\begin{array}{l}\text { Summary of } \\
\text { evidence }\end{array}$ & 24 & $\begin{array}{l}\text { Summarize the main findings including the strength of evidence for each main } \\
\text { outcome; consider their relevance to key groups (eg, healthcare providers, users, and } \\
\text { policy makers). }\end{array}$ & $17-19$ \\
\hline Limitations & 25 & $\begin{array}{l}\text { Discuss limitations at study and outcome level (eg, risk of bias), and at review-level } \\
\text { (eg, incomplete retrieval of identified research, reporting bias). }\end{array}$ & 19 \\
\hline Conclusions & 26 & $\begin{array}{l}\text { Provide a general interpretation of the results in the context of other evidence, and } \\
\text { implications for future research. }\end{array}$ & 20 \\
\hline \multicolumn{4}{|l|}{ Funding } \\
\hline Funding & 27 & $\begin{array}{l}\text { Describe sources of funding for the systematic review and other support (eg, supply of } \\
\text { data); role of funders for the systematic review. }\end{array}$ & $\begin{array}{l}\text { Declared on online } \\
\text { PLoS submission } \\
\text { system }\end{array}$ \\
\hline
\end{tabular}

Figure SI PRISMA checklist.

Notes: Reproduced from Moher D, Liberati A, Tetzlaff J, Altman DG, PRISMA Group. Preferred reporting items for systematic reviews and meta-analyses: the PRISMA statement. PLoS Med. 2009;6(6):el 000097. ${ }^{10}$ For more information, visit: www.prisma-statement.org.

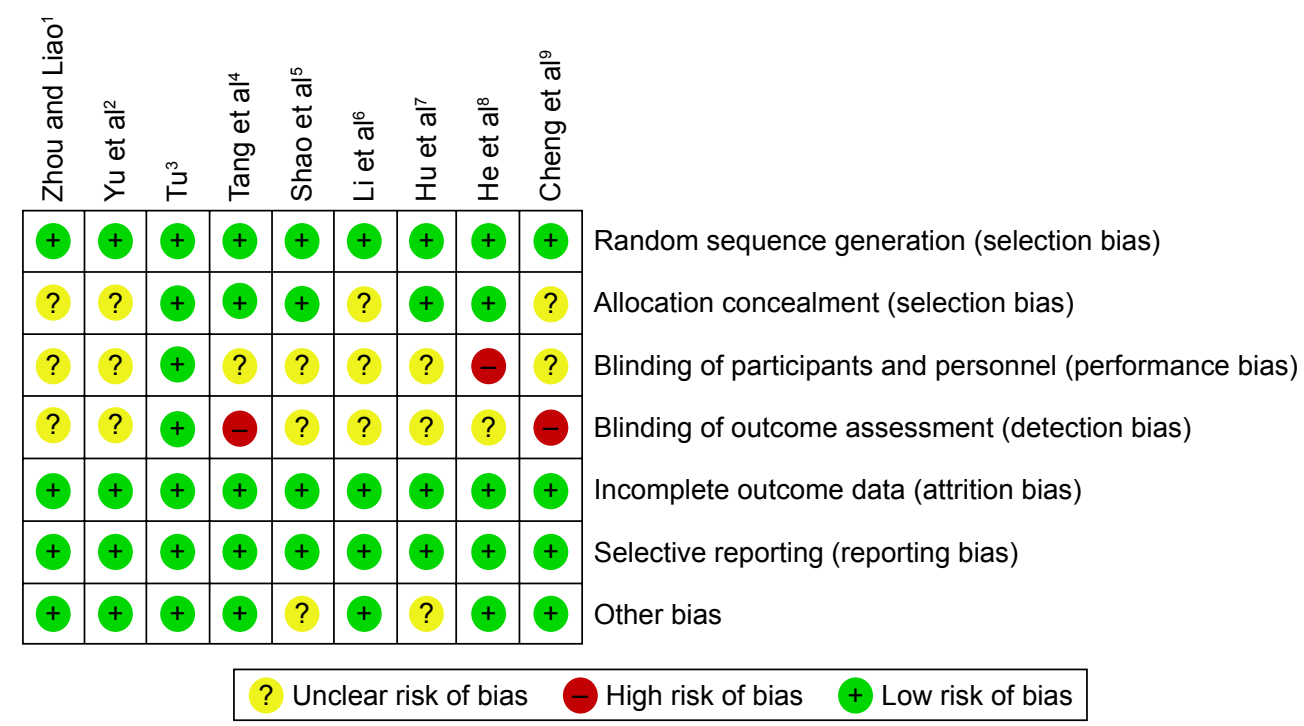

Figure S2 Risk of bias and applicability concerns graph: review authors' judgments about each domain presented as percentages across included studies. 


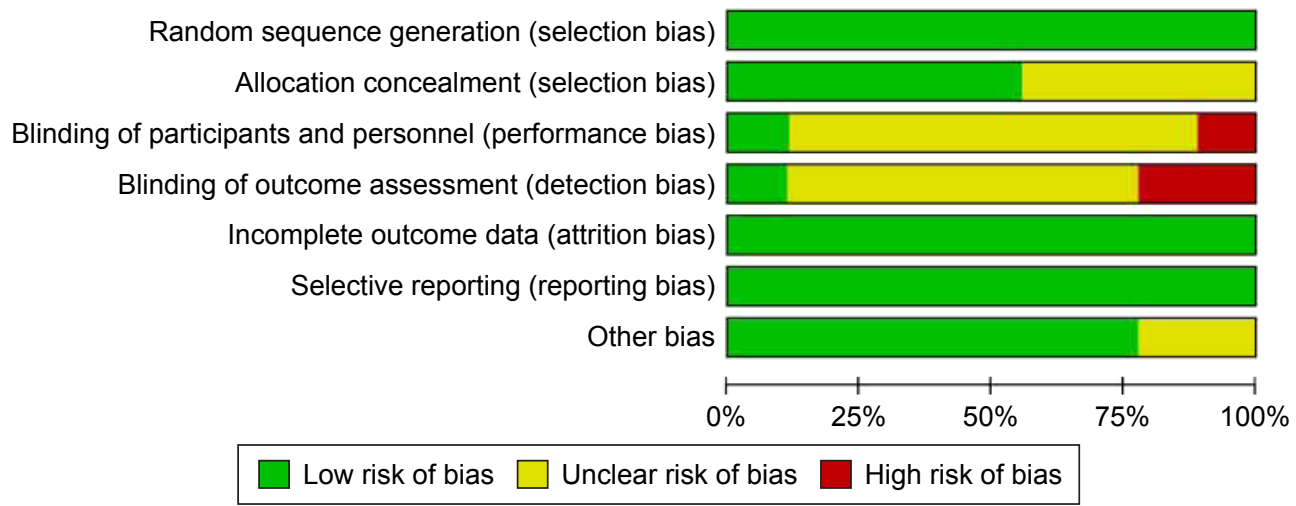

Figure S3 Risk of bias and applicability concerns summary: review authors' judgments about each domain for each included study.

\section{References}

1. Zhou TZ, Liao ZW. Clinical study of nimotuzumab and three dimensional conformal radiotherapy in the treatment of recurrent nasopharyngeal carcinoma. Inter Med Health Guidance News. 2013;19(21):3257-3260.

2. Yu HW, Zhuag YJ, Yu F, Liao ZW, Zhou TC. Clinical study of nimotuzumab combined with cisplatin and three-dimensional conformal radiotherapy in treatment of nasopharyngeal carcinoma. Guangxi Med J. 2014; 36(7):882-884

3. Tu BJ. Clinical studies of Montezuma combined with cisplatin and three-dimensional conformal radiotherapy chemotherapy in the treatment of nasopharyngeal carcinoma. Guangzhou University; 2013. Available from: http://d.g.wanfangdata.com.cn/Thesis_D375768.aspx. Accessed November 1, 2017.

4. Tang WB, Yang W, Cao Y, et al. Effect of nimotuzumab combined with radiotherapy and chemotherapy for locally advanced nasopharyngeal carcinoma. Guangdong Med. 2012;33(11):1658-1662.

5. Shao JF, Li SP, Lian YN, Mao JX, Mo YM. Clinical study of nimotuzumab plus nadaplatin combined with concurrent chemoradiotherapy for locally advanced nasopharyngeal carcinoma. Modern Med J Chin. 2014;4(1):23-26.
6. Li D, Bai Y, Xie K, Ao R. Efficacy and safety of nimotuzumab combined with nedaplatin and three-dimensional conformal concurrent radiotherapy for nasopharyngeal cancer chemotherapy and the impact of TGF- $\beta 1$, S100A8 and S100A9. J Med Res. 2015;44(11):136-139.

7. Hu JX, Gu WG, He ZR, Luo HT, Xu M. Short-term effect of nimotuzumab combined with chemoradiotherapy for advanced nasopharyngeal carcinoma. Guangdong Med J. 2013;34(13):2094-2096.

8. He N, Si YF, Sun YJ, et al. Effect of nimotuzumab combined with concurrent chemoradiotherapy for locally advanced nasopharyngeal carcinoma. Guangxi Med J. 2013;35(7):834-837.

9. Cheng J, Xun X, Li GH. Clinical utility of nimotuzumab with cisplatin and chemoradiotherapy in advanced nasopharyngeal carcinoma. Hebei Med J. 2016;22(2):213-215.

10. Moher D, Liberati A, Tetzlaff J, Altman DG, PRISMA Group. Preferred reporting items for systematic reviews and meta-analyses: the PRISMA statement. PLoS Med. 2009;6(6):e1000097.
OncoTargets and Therapy

\section{Publish your work in this journal}

OncoTargets and Therapy is an international, peer-reviewed, open access journal focusing on the pathological basis of all cancers, potential targets for therapy and treatment protocols employed to improve the management of cancer patients. The journal also focuses on the impact of management programs and new therapeutic agents and protocols on

\section{Dovepress}

patient perspectives such as quality of life, adherence and satisfaction The manuscript management system is completely online and includes a very quick and fair peer-review system, which is all easy to use. Visit http://www.dovepress.com/testimonials.php to read real quotes from published authors. 